\title{
Modifikasi Perencanaan Struktur Gedung Grand Dharmahusada Lagoon Menggunakan Struktur Komposit Baja Beton CFT dengan Sistem Rangka Bresing Eksentris Tipe Two-Story- $X$ Braced
}

\author{
Pelangi S. Maharani, dan Faimun \\ Departemen Teknik Sipil, Fakultas Teknik Sipil, Lingkungan, dan Kebumian \\ Institut Teknologi Sepuluh Nopember (ITS) 60111 Indonesia \\ e-mail: faimun@ce.its.ac.id
}

\begin{abstract}
Abstrak- Sistem rangka bresing merupakan salah satu pilihan untuk perencanaan gedung baja tahan gempa. Sistem tersebut adalah salah satu pilihan yang lebih mudah untuk diaplikasikan di Indonesia dikarenakan ketersediaan bahannya yang mudah didapat. Sistem rangka bresing eksentris merupakan modifikasi dari bresing konsentris, dimana bagian yang harus leleh adalah bagian link sehingga untuk memastikan terjadinya pelelehan pada bagian tersebut menjadi lebih mudah. Gedung Apartemen Grand Dharmahusada Lagoon akan direncanakan ulang dengan menggunakan struktur baja beton komposit ConcreteFilled Steel Tube atau CFT dengan sistem penahan lateral bresing eksentris atau eccentrically braced frames (EBF) dengan sistem yang memiliki ketinggian 20 lantai dan 1 basement. Konfigurasi yang digunakan adalah Two-Story-XBraced. Perencanaan akan memenuhi persyaratan keamanan struktur berdasarkan 1729:2015, SNI 03-1729-2002, SNI 1726:2012, SNI 2847:2013, dan SNI 1727:2013. Dari hasil Analisa yang telah dilakukan diperoleh hasil yaitu: tebal pelat lantai dan atap dengan menggunakan bondek ialah $10 \mathrm{~cm}$, dimensi balok induk WF $600 \times 300 \times 14 \times 23$, panjang elemen link $200 \mathrm{~cm}$ dengan dimensi WF $500 \times 200 \times 9 \times 14$, dimensi bresing WF $500 \times 200 \times 11 \times 19$, dimensi kolom CFT $700 \times 700 \times 40$. Perencanaan bangunan bawah menggunakan dinding penahan dengan tipe cantilever wall beton dan pondasi menggunakan tiang pancang beton dengan diameter $80 \mathrm{~cm}$ dan kedalaman 28 meter. Dimensi sloof 30/40.
\end{abstract}

Kata Kunci-Baja Daktail, Eccentrically-Braced Frames, Concrete-Filled Steel Tube.

\section{PENDAHULUAN}

$\mathrm{R}$ ING of Fire, atau yang biasa disebut Lingkaran Api Pasifik adalah sebuah kawasan yang sering mengalami gempa bumi dan letusan gunung berapi yang mengelilingi cekungan Samudra Pasifik. Indonesia sendiri berada di jalur gempa teraktif di dunia karenadikelilingi oleh Cincin Api Pasifik dan berada di atas tiga tumbukan lempeng benua, yakni Indo-Australia dari sebelah selatan, Eurasia dari utara, dan Pasifik dari timur. Kondisi geografis tersebut menjadikan Indonesia sebagai sebuah wilayah yang memiliki tingkat aktivitas gempa bumi tinggi.

Oleh karena itu, diperlukan struktur bangunan yang tahan gempa. Maksud dari tahan gempa adalah: struktur bangunan tidak boleh mengalami kerusakan jika terjadi gempa bumi dengan kekuatan ringan, Jika terjadi gempa bumi berkekuatan sedang atau menengah kerusakan struktur boleh terjadi terbatas pada kerusakan ringan dan dapat diperbaiki.
Sedangkan jika terjadi gempa bumi dengan kekuatan besar bangunan tidak boleh roboh, meskipun sudah mengalami kerusakan yang parah; sehingga korban jiwa manusia dikurangi meskipun terjadi kerusakan dan kerugian material.

Gedung Apartemen Grand Dharmahusada Lagoon merupakan gedung yang akan dibangun di Surabaya. Gedung tersebut pada awalnya didesain dengan menggunakan struktur beton bertulang konvensional dan akan dimodifikasi menjadi baja komposit tipe Concrete-Filled Steel Tube (CFT) pada kolomnya dan juga menggunakan bresing tipe Eccentrically Braced Frames (EBF) dengan modelnya sendiri Two Story X-Braced.

Struktur komposit merupakan struktur yang terdiri dari dua material atau lebih dengan sifat bahan yang berbeda dan membentuk satu kesatuan sehingga menghasilkan sifat gabungan yang lebih baik, sehingga akan menghasilkan desain profil/elemeyang lebih ekonomis. Struktur komposit pada aplikasinya merupakan elemen dari bangunan itu sendiri, baik sebagai kolom, balok ataupun pelat [1].

Untuk gedung tinggi, ukuran dari kolom komposit seringkali jauh lebih kecil dari yang diharuskan untuk kolom beton bertulang untuk menahan beban yang sama. Hasil yang didapat dari desain komposit adalah bisa menghemat area lantai. Dalam struktur komposit terdapat 2 tipe kolom komposit yaitu tabung atau pipa baja yang dicor beton (Concrete-Filled Steel Tube (CFT)) dan baja profil yang diselimuti beton dengan tulangan longitudinal dan diikat dengan tulangan lateral. Untuk perencanaan ini, tipe struktur kolom komposit yang digunakan adalah tipe Concrete-Filled Steel Tube atau CFT.

CFT merupakan struktural komposit yang terdiri dari tabung baja dan beton pengisi. Komposit struktur ini mengoptimalkan kontribusi kedua komponen dengan meningkatkan efisiensi geometris mereka dan menggabungkan kekuatan yang melekat dari keduanya. Dinding pengisi beton dibatasi oleh tabung baja, sehingga dalam keadaan triaksial kompresi dapat meningkatkan kekuatan dan kapasitas regangan beton. Pengisian beton pada baja perimeter secara optimal, dapat menunda terjadinya local-global buckling tabung. Struktur ini mudah dan cepat dibangun dan menghasilkan kompresi yang signifikan [2].

Gedung Apartemen Grand Dharmahusada Lagoon akan direncanakan ulang dengan menggunakan kolom komposit tipe Concrete-Filled Steel Tube atau CFT dengan sistem penahan lateral bresing eksentris (EBF) dikarenakan 
keunggulan yang ditawarkan mampu menunjang kebutuhan akan gedung kokoh yang akan dibangun di daerah rawan gempa.

\section{TINJAUAN PUSTAKA}

Struktur komposit merupakan struktur yang terdiri dari dua material atau lebih dengan sifat bahan yang berbeda dan membentuk satu kesatuan sehingga menghasilkan sifat gabungan yang lebih baik, sehingga akan menghasilkan desain profil/elemen yang lebih ekonomis. Struktur komposit pada aplikasinya merupakan elemen dari bangunan itu sendiri, baik sebagai kolom, balok ataupun pelat [1].

Kolom komposit baja yang contohnya seperti pada Gambar 1 terisi beton atau Concrete Filled Tube (CFT) dibuat dengan cara mengisi beton pada profil baja berongga berbentuk lingkaran atau segi empat. Pada kolom komposit CFT lingkaran, kekuatan tekan beton di dalam profil baja berongga dapat meningkat mencapai 50\% dari kuat tekan silinder beton tanpa pengekangan akibat efek pengekangan dari profil baja berongga [3].
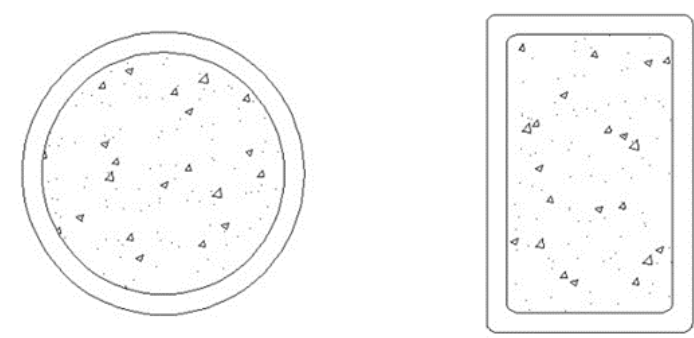

Gambar 1. Kolom Komposit dari Penampang Baja Berongga.

Ide utama dari desain dari struktur rangka berpengaku eksentrik atau Eccentrically Braced Frame (EBF) adalah untuk menyatukan keuntungan dari Moment Resisting Frame (MRF) dan Concentrically Braced Frame (CBF) yaitu sistem yang menahan beban lateral menjadi sebuah sistem structural. Sistem EBF, yang konfigurasinya ada berbagai macam seperti pada Gambar 2, berasal dari Jepang di 1970 dengan tujuan untuk mendapatkan struktur dengan kekakuan elastis yang tinggi dan juga kehilangan energi yang tinggi ketika gempa bumi besar [4].

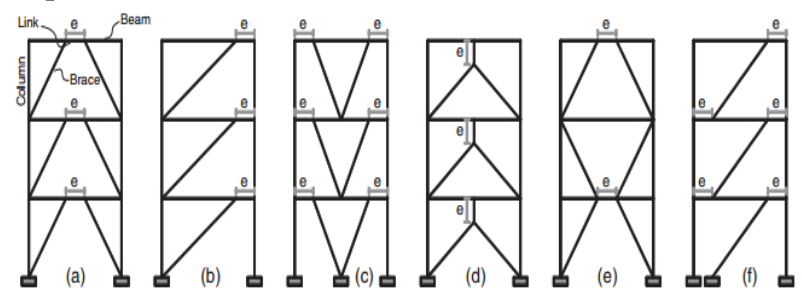

Gambar 2. Konfigurasi EBF

Panjang dari segmen link (e) adalah salah satu dari parameter kunci yang mengontrol kekakuan, kekuatan, daktilitas, dan tingkah laku dari sebuah sistem EBF. Ada beberapa perbedaan substansi antara tingkah laku dari link yang panjang dan yang pendek. Meskipun link yang lebih panjang menghasilkan kebebasan arsitektural untuk bukaan, studi dan percobaan awal oleh Roeder dan Popov dan Hjelmstad dan Popov menunjukkan bahwa performa dari link pendek jauh lebih baik dibandingkan dengan link panjang di bawah beban siklik yang kuat dalam kekuatan dan daktilitas [4].

Gaya aksial yang tinggi di balok di luar dari link dapat mempersulit pemilihan balok apabila balok di luar link dan balok untuk link adalah balok yang sama, apalagi jika seukuran. Gaya aksial tersebut dapat dikurangi atau dihilangkan dengan pemilihan konfigurasi yang menguntungkan. Portal dengan link di tengah bisa dikonfigurasi ulang untuk menghilangkan gaya aksial pada balok dengan membuat konfigurasi two-story-x braced EBF seperti pada Gambar 3 [5].

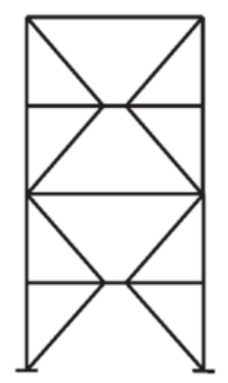

Gambar 3. Konfigurasi Two-Story X-Braced

\section{METODOLOGI}

Urutan penyelesaian perencanaan ini dapat dilihat pada bagan alir pada Gambar 4:

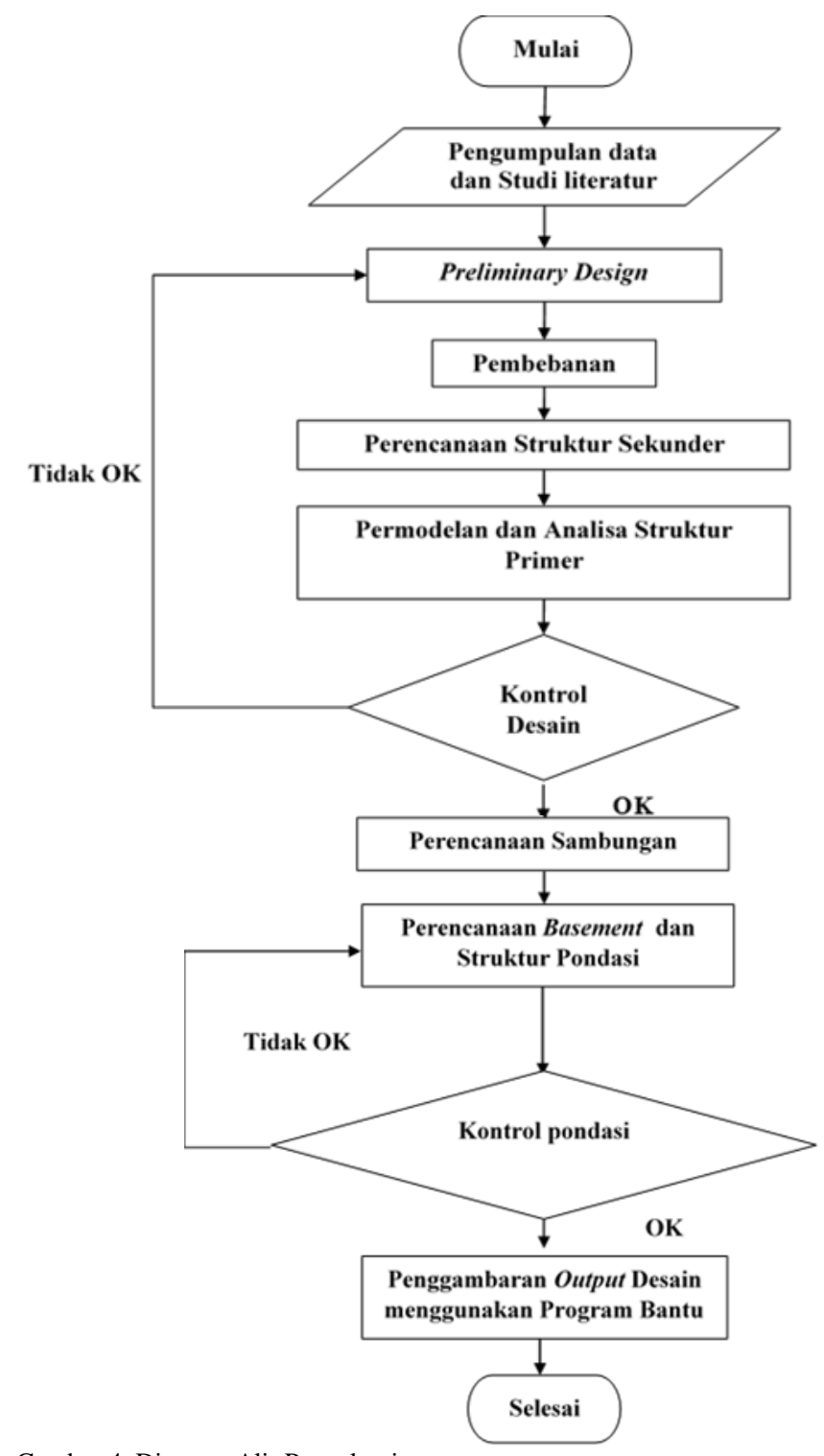

Gambar 4. Diagram Alir Penyelesaian

Adapun pada perencanaan ini akan dimodifikasi perencanaannya menggunakan material baja dengan datadata sebagai berikut : 
1. Nama Gedung : Grand Dharmahusada Lagoon

2. Lokasi : Yogyakarta, DIY

3. Fungsi : Apartement

4. Tinggi $: \pm 71.40 \mathrm{~m}$

5. Jumlah Lantai : 21 (1 lantai basement, 19 lantai Apartement, 1 lantai atap)

6. Struktur Utama : Balok baja dengan dek dan kolom Concrete Filled Steel-Tube

Adapun kriteria desain dari perencanaan gedung tersebut adalah sebagai berikut:

1. Struktur Utama: Bangunan Baja dengan kolom ConcreteFilled Steel Tube.

2. Sistem Gedung: Eccentrically-Braced Frames

3. Pembebanan
a. Beban Mati: SNI 1727:2013 Pasal 3.1.1
b. Beban Hidup: SNI 1727:2013 Pasal 4
c. Beban Gempa: SNI 1726:2012
d. Kombinasi Pembebanan: SNI 1727:2013 Pasal 3.2.2

4. LINK \& BRACING
a. BJ 41
b. AISC Seismic Provisions for Structural Steel Building Section F.3 (Eccentrically Braced Frames)
c. SNI 1729:2012 Pasl 15.13.2 (Link)

5. BALOK KOMPOSIT
a. BJ41
b. Beton f'c 40
c. AISC Design Examples Version 15.0, Example I.1

6. KOLOM CFT
a. SNI 1729:2015 BAB I
b. SNI 1729:2015 Lampiran 8

7. SAMBUNGAN
a. BAUT
i. A325
ii. SNI 1729:2015 pasal J.3

b. LAS
i. FE70XX
ii. SNI 1729:2015 pasal J2.4

8. BASE PLATE

a. AISC Design Examples Version 15.0, Example K.9

b. AISC Design Examples Version 15.0, Example I.12

9. BASEMENT
a. DINDING
i. f'c $35 \mathrm{MPa}$
ii. fy $420 \mathrm{MPa}$
iii. SNI 2847:2013
b. PELAT
i. f'c $35 \mathrm{Mpa}$
ii. fy $420 \mathrm{MPa}$
c. SNI 2847:2013

10. PONDASI
a. TIANG PANCANG
i. f'c $52 \mathrm{Mpa}$
ii. SNI 1726:2012
b. PILE CAP
i. f'c $40 \mathrm{MPa}$
ii. fyt $420 \mathrm{MPa}$
iii. SNI 2847:2013
iv. SNI 1726:2012
c. SLOOF
i. f'c $40 \mathrm{MPa}$
ii. fyt $420 \mathrm{Mpa}$
iii. SNI 2847:2013

\section{HASIL DAN PEMBAHASAN}

\section{A. Perencanaan Struktur Sekunder}

1) Pelat atap dan lantai

Pelat lantai atap dan lantai apartemen direncanakan menggunakan bondek dari Super Floor Deck dengan tebal 0,75 mm. Hasil perhitungan struktur pelat ini tersaji pada Tabel 1.

Tabel 1.

Rekapitulasi Perhitungan Pelat

\begin{tabular}{cccc}
\hline \hline Fungsi & Bentang & Tebal Pelat (cm) & Tulangan \\
\hline Ruang Publik & 3 & 10 & M5-110 \\
Lantai & 3 & 10 & M5-110 \\
Atap & 3 & 10 & M8-140 \\
\hline \hline
\end{tabular}

2) Perencanaan Balok Sekunder

Balok sekunder direncanakan menggunakan Wide Flange (WF) BJ-41 dengan profil yang tersaji dalam Tabel 2.

Dimensi Balok Anak

\begin{tabular}{clcc}
\hline \hline No & \multicolumn{1}{c}{ Fungsi } & Bentang & Profil \\
\hline 1 & Ruang Publik & 6 & WF $500 \times 200 \times 11 \times 19$ \\
2 & Lantai & 6 & WF $500 \times 200 \times 11 \times 19$ \\
3 & Atap & 6 & WF $500 \times 200 \times 11 \times 19$ \\
\hline \hline
\end{tabular}

3) Perencanaan Tangga dan Bordes

Tangga adalah sebuah konstruksi yang dirancang untuk menghubungi dua tingkat vertikal yang memiliki jarak satu sama lain.

Data Teknis Perencanaan Tangga

$\begin{array}{ll}\text { - } \text { Tinggi antar lantai } & =340 \mathrm{~cm} \\ \text { - } \quad \text { Tinggi bordes } & =170 \mathrm{~cm} \\ \text { - } \quad \text { Panjang tangga tanpa bordes } & =300 \mathrm{~cm} \\ \text { - Lebar tangga } & =130 \mathrm{~cm} \\ \text { - } \quad \text { Panjang bordes } & =150 \mathrm{~cm} \\ \text { - Lebar bordes } & =275 \mathrm{~cm} \\ \text { - Lebar antrede (i) } & =30 \mathrm{~cm} \\ \text { - Lebar penyangga tangga } & =15 \mathrm{~cm}\end{array}$

Tabel 3.

Dimensi Tangga

\begin{tabular}{clc}
\hline \hline No & \multicolumn{1}{c}{ Jenis Struktur } & Ket. Profil \\
\hline 1 & Pelat Anak Tangga & Pelat t $=4 \mathrm{~mm}$ \\
2 & Pengaku Pelat Anak Tangga & L $50 \times 50 \times 7$ \\
3 & Pelat Bordes & Pelat t $=6 \mathrm{~mm}$ \\
4 & Balok Bordes & WF $100 \times 50 \times 5 \times 7$ \\
5 & Balok Utama Tangga & WF $250 \times 125 \times 5 \times 8$ \\
6 & Balok Penumpu Tangga & WF $250 \times 125 \times 5 \times 8$ \\
\hline \hline
\end{tabular}

4) Perencanaan Lift

Pada bangunan ini menggunakan lift penumpang dengan data-data sebagai berikut:
Tipe lift
: Passenger Elevators
Merek
: SIGMA
Kapasitas
: 24 orang / $1600 \mathrm{~kg}$
Lebar pintu (opening width): $1100 \mathrm{~mm}$
Jumlah Terpasang $\quad: 1$
Dimensi balok penggantung lift menggunakan profil WF $350 \times 250 \times 9 \times 14$.

\section{B. Permodelan Struktur}

Perencanaan dimodelkan pada aplikasi permodelan seperti pada Gambar 5. 


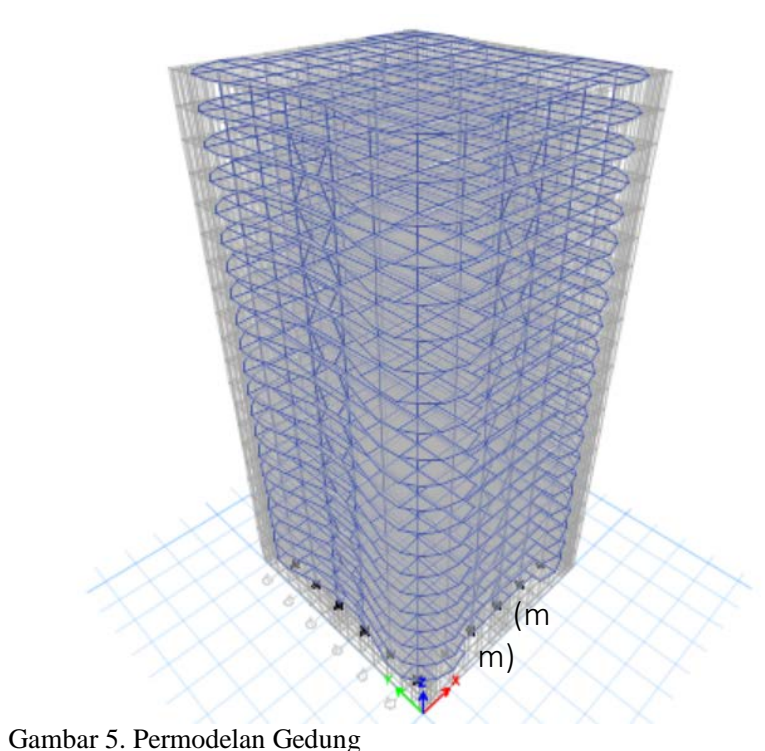

Gambar 5. Permodelan Gedung

Pada permodelan di aplikasi tersebut, untuk elemenelemen seperti balok link, balok bresing, balok induk, balok anak dan kolom dimodelkan dengan menggunakan Frame. Sedangkan untuk permodelan pelat menggunakan Deck.

Gempa menggunakan respons spektrum, dengan lokasi di Jogja dan kelas situs E. Didapat SDS = 0,964 dan SD1 = 0,896 . Sistem ganda rangka baja dengan bresing eksentris menggunakan koefisien seperti di bawah ini:

$$
\begin{aligned}
& \mathrm{R}=8 \\
& \Omega=2,5 \\
& \mathrm{Cd}=4
\end{aligned}
$$

\section{Kontrol Desain}

Karena besarnya beban gempa sangat dipengaruhi oleh berat dari struktur bangunan, maka perlu diketahui berat total bangunan untuk menentukan gaya geser statik. Berat dari bangunan berasal dari beban mati yang terdiri dari berat sendiri material-material bangunan dan elemen-elemen struktur, serta beban hidup yang diakibatkan oleh hunian atau penggunaan bangunan.

\section{1) Kontrol Berat Bangunan}

Berat total struktur perhitungan manual $=22.031 .232 \mathrm{~kg}$

Berat total struktur permodelan $\quad=21.368 .399 \mathrm{~kg}$

Sehingga diperoleh persentase:

$$
\frac{662.832}{22.031 .232} \times 100 \%=3 \%<5 \%(O K)
$$

2) Kontrol Partisipasi Massa

Partisipasi massa harus menyertakan jumlah ragam terkombinasi minimal 90\% dari massa aktual yang berasal dari masing-masing arah horizontal dan orthogonal yang ditinjau.

Tabel 4

Kontrol Nilai Partisipasi Massa

\begin{tabular}{cccc}
\hline \hline Case & Mode & Sum UX & Sum UY \\
\hline Modal & 7 & $\mathbf{0 , 9 1 5 5}$ & 0,8783 \\
Modal & 8 & 0,9155 & $\mathbf{0 , 9 1 5 5}$ \\
\hline \hline
\end{tabular}

\section{3) Kontrol Waktu Getar Alami Fundamental}

Perkiraan periode alami fundamental (Ta) dalam detik, harus ditentukan dengan persamaan berikut:

$\mathrm{Ta}=\mathrm{Ct} . \mathrm{hn}^{\mathrm{x}} ; \mathrm{Ct}=0,0731 ; \mathrm{x}=0,75 ; \mathrm{hn}=71,4 \mathrm{~m}$

$\mathrm{Ta}=0,0731.71,4^{0,75}=1,79$ detik

Dengan nilai SD1 $=0,496$, maka $\mathrm{Cu}=1,4$

Sehingga periode sruktur yang diijinkan adalah :

$$
\mathrm{T}=\mathrm{Ta} . \mathrm{Cu}=1,79 \times 1,4=2,506 \text { detik }
$$

Tabel 5.

Kontrol Waktu Getar Alami Fundamental

\begin{tabular}{crc}
\hline \hline \multirow{2}{*}{ Case } & Mode & Period \\
\cline { 3 - 3 } & & sec \\
\hline Modal & 1 & 2,271 \\
Modal & 2 & 2,271 \\
Modal & 3 & 2,125 \\
\hline \hline
\end{tabular}

Dari Tabel 5, Tc $=2,271 \mathrm{~s}$, maka berdasarkan kontrol waktu getar alami fundamental, nilai T masih lebih kecil dari Cu.T. Jadi analisis struktur memenuhi syarat.

4) Kontrol Nilai Akhir Respon Spektrum

Kombinasi respons untuk gaya geser dasar ragam dinamik (Vt) harus lebih besar 85\% dari gaya geser dasar statik (V) atau $\left(\mathrm{V}_{\text {dinamik }} \geq 0,85 \mathrm{~V}_{\text {statik }}\right)$ seperti pada Tabel 6 .

Tabel 6.

Kontrol Nilai Akhir Respon Spektrum 1

\begin{tabular}{lllc}
\hline \hline Ket & $\mathbf{V}_{\text {dinamik }}(\mathbf{k g})$ & $\mathbf{V}_{\text {statik }}(\mathbf{k g})$ & $\mathbf{V}_{\text {dinamik }} \geq \mathbf{V}_{\text {statik }}$ \\
\hline RSX & $804.753,37$ & $834.406,95$ & NOT OK \\
RSY & $804.770,29$ & $834.406,95$ & NOT OK \\
\hline \hline
\end{tabular}

Dikarenakan hasilnya tidak memenuhi syarat, maka dikalikan dengan angka terbesar yang didapat dari $\mathrm{V}_{\text {statik }}$

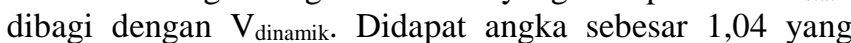
kemudian dikalikan pada scale factor yang kemudian hasilnya seperti pada Tabel 7.

Tabel 7.

Kontrol Nilai Akhir Respon Spektrum 2

\begin{tabular}{lllc}
\hline \hline Ket & $\mathbf{V}_{\text {dinamik }}(\mathbf{k g})$ & $\mathbf{V}_{\text {statik }}(\mathbf{k g})$ & $\mathbf{V}_{\text {dinamik }} \geq \mathbf{V}_{\text {statik }}$ \\
\hline RSX & $834.886,2$ & $834.406,95$ & OK \\
RSY & $834.886,2$ & $834.406,95$ & OK \\
\hline \hline
\end{tabular}

\section{5) Kontrol Batas Simpangan (Drift)}

Gempa menyebabkan struktur bertingkat rawan terhadap terjadinya simpangan horizontal (Drift). Dan apabila simpangan horizontal ini melebihi syarat aman yang telah ditentukan maka gedung akan mengalami keruntuhan dengan simpangan maksimum $68 \mathrm{~mm}$.

\section{Drift}

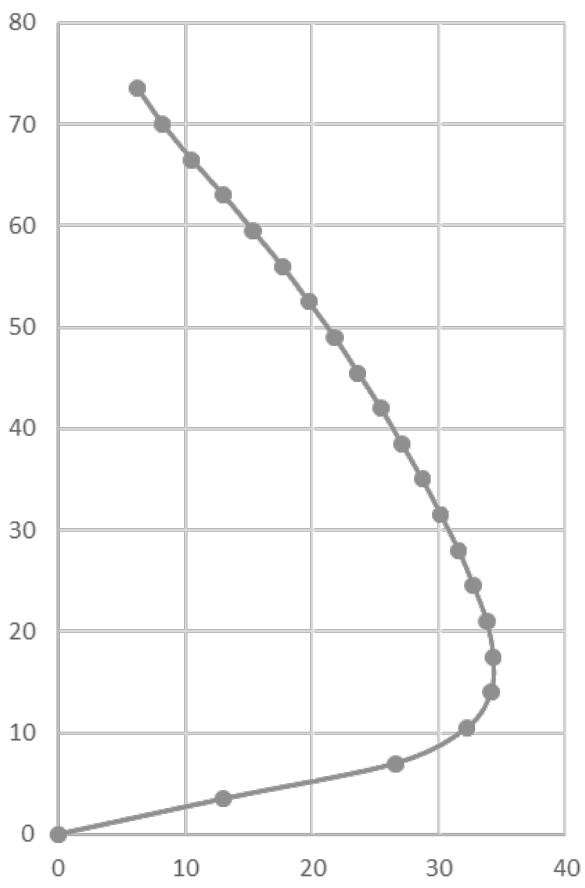

Gambar 6. Grafik Drift 


\section{6) Kontrol Dual Sistem}

Berdasarkan SNI 1727:2012 Pasal 7.2.5.1, Sistem Rangka Pemikul Momen (SRPM) harus memikul minimum 25\% dari beban geser nominal total yang bekerja dalam arah kerja beban gempa tersebut. Berikut total reaksi perletakan SRPM dan SRBE.

Tabel 7.

Perbandingan SRPM dan SRBE

\begin{tabular}{ccccc}
\hline \hline \multirow{2}{*}{ Pemikul Gaya Geser } & \multicolumn{2}{c}{ Gempa X } & \multicolumn{2}{c}{ Gempa Y } \\
\cline { 2 - 5 } & kgf & $\mathbf{\%}$ & kgf & $\mathbf{\%}$ \\
\hline SRBE & 214392,27 & 21 & 214559,89 & 21 \\
SPRM & 816648,69 & 79 & 816496,31 & 79 \\
Total & 1031040,96 & 100 & 1031056,2 & 100 \\
\hline \hline
\end{tabular}

D. Perencanaan Struktur Primer

\section{1) Perencanaan Link}

Link adalah elemen utama dari system rangka bresing eksentris, dimana elemen tersebut harus menjadi elemen yang kalah dibandingkan dengan elemen lainnya.

Balok link direncanakan menjadi link dominan lentur, atau nama lainnya adalah link panjang, dikarenakan deformasi yang dapat dilakukan oleh gedung ketika gempa terjadi jauh lebih besar daripada link pendek. Syarat dari link panjang adalah seperti rumus di bawah ini:

$$
\frac{2,6 M_{p}}{V_{p}} \leq e
$$

Balok link, seperti pada Gambar 7, direncanakan menggunakan profil WF 500x300x11x15. Panjang link = 200 $\mathrm{cm}$. Berdasarkan persamaan di atas, link merupakan link lentur.

Dari output aplikasi permodelan diperoleh gaya dalam yang dipakai dalam desain adalah:
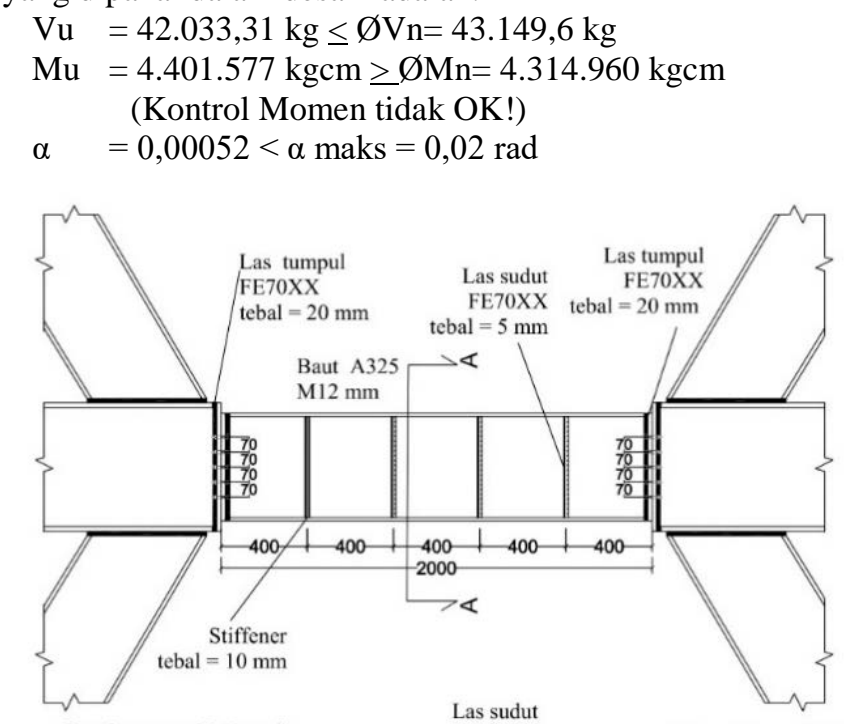

Gambar 7. Balok link

Balok link direncanakan terpisah dari balok induk untuk mempermudah perbaikan gedung ketika terjadi gempa, sehingga link yang leleh atau rusak dapat diganti dan gedung dapat berfungsi seperti sedia kala.

2) Perencanaan Bresing

Konfigurasi bresing direncanakan menggunakan tipe TwoStory- $X$ Braced seperti pada gambar 8, dimana gaya dari bresing dua lantai mempengaruhi satu link. Hal tersebut membuat gaya yang didapat oleh link tersebut menjadi dua kali lipat lebih besar daripada menggunakan konfigurasi bresing EBF pada umumnya. Sehingga, penampang dari balok link yang didapat berdasarkan kelelehan dapat menjadi lebih kecil.

Balok direncanakan menggunakan profil WF 500x200x11x19. Dari output aplikasi permodelan diperoleh gaya dalam yang dipakai dalam desain adalah:

$$
\phi_{c} P_{n}=281.450,27>P u=136.439,32 \mathrm{~kg}
$$

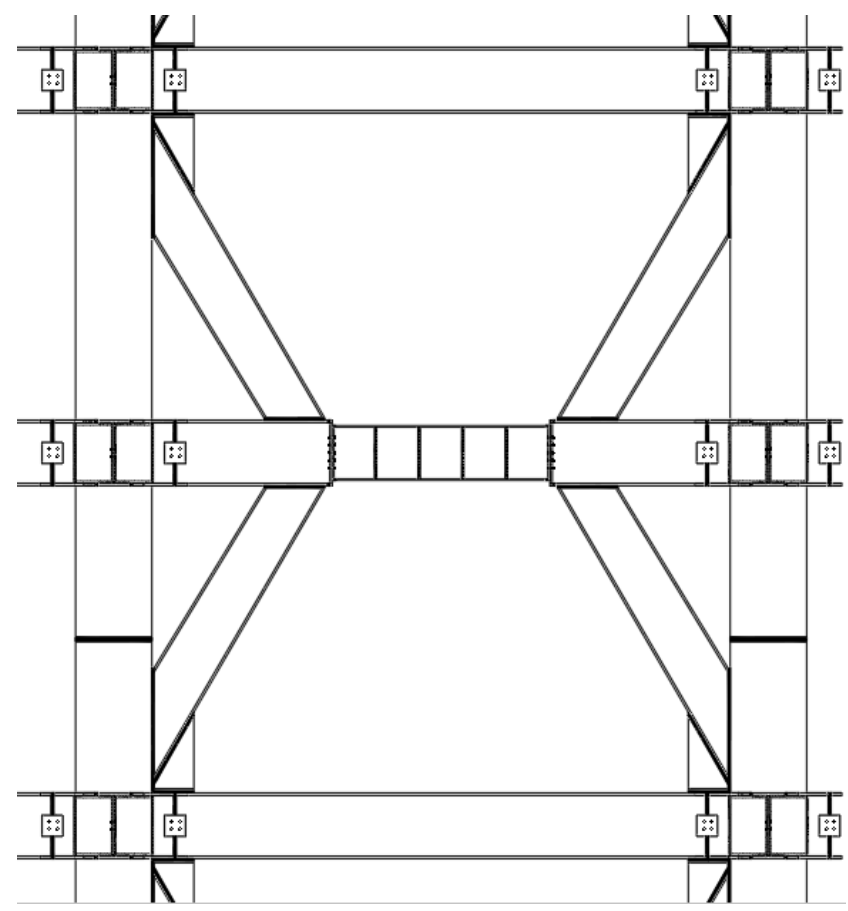

Gambar 8. Konfigurasi bresing Two-Story- $X$ Braced

\section{3) Perencanaan Balok Induk}

Dikarenakan sistem struktur yang digunakan pada permodelan merupakan sistem ganda rangka baja dengan bresing eksentris dimana pada bangunan tersebut balok harus dapat berdeformasi, maka balok harus direncanakan lebih lemah daripada kolom yang digunakan. Untuk penjelasannya akan dijelaskan pada bagian perencanaan kolom CFT.

Balok direncanakan menggunakan profil WF 700x300x28x15. Dari output aplikasi permodelan diperoleh gaya dalam yang dipakai dalam desain adalah:

Sebelum Komposit

$$
\begin{array}{ll}
\mathrm{Mu} & =43.597,71 \mathrm{~kg} \cdot \mathrm{m} \leq \varnothing \mathrm{Mn}=112.882,5 \mathrm{~kg} \cdot \mathrm{m} \\
\mathrm{Vu} & =19.970,61 \mathrm{~kg} \leq \varnothing \mathrm{Vn}=75141 \mathrm{~kg} \\
\mathrm{f}^{0} & =0,057 \mathrm{~cm} \leq \mathrm{f} \text { ijin }=1,52 \mathrm{~cm}
\end{array}
$$

Setelah Komposit

$$
\begin{aligned}
& \mathrm{Mu}^{+}=35.743 \mathrm{~kg} \cdot \mathrm{m} \leq \varnothing \mathrm{Mn}=187.282 \mathrm{~kg} \cdot \mathrm{m} \\
& \mathrm{Mu}^{-}=45.525,04 \mathrm{~kg} \cdot \mathrm{m} \leq \varnothing \mathrm{Mn}=144.920,55 \mathrm{~kg} \cdot \mathrm{m} \\
& \mathrm{Vu}=20.636,51 \mathrm{~kg} \leq \varnothing \mathrm{Vn}=92.988 \mathrm{~kg} \\
& \mathrm{f}^{0} \quad=0,054 \mathrm{~cm} \leq \mathrm{f} \text { ijin }=1,74 \mathrm{~cm}
\end{aligned}
$$

Shear Connector

$$
\begin{aligned}
& \mathrm{N}=\frac{\mathrm{V} h}{Q n}=\frac{233.750}{14.700}=15,9=16 \text { buah } \\
& 2 \mathrm{~N}=2 \times 16=32 \text { buah } \\
& \mathrm{S}=\frac{\mathrm{L}}{\mathrm{N}}=\frac{550}{32}=17 \mathrm{~cm}
\end{aligned}
$$

\section{4) Kolom CFT}

Selain interaksi antara balok dengan kolom untuk memastikan permodelan dapat digunakan, kolom juga harus dikontrol secara tiga hal: aksial tekan, tekuk lokal, dan tekuk lateral.

Kolom direncanakan menggunakan profil CFT 700 x 700 x 40 dengan kontrol kuat nominal penampang sebagai berikut: 
Kontrol Tekan:

$\mathrm{Pp}=\mathrm{Pno}=3.910 .240 \mathrm{~kg}>\mathrm{Pu}=988.955,91 \mathrm{~kg}$

Kontrol Tekuk Lokal:

$\mathrm{Mn}=\mathrm{Mp}=480.150 \mathrm{kgm}>\mathrm{Mu}=99.347,32 \mathrm{kgm}$

Kontrol Tekuk Lateral:

$\mathrm{Mn}=\mathrm{Mp}=533.500 \mathrm{kgm}>\mathrm{Mu}=99.347,32 \mathrm{kgm}$

Rumus Interaksi:

$\frac{P_{r}}{\emptyset P_{c}}=\frac{1.180 .043,64}{0,9 \times 3.910 .240}=0,33 \geq 0,2$

Kontrol Interaksi "Balok - Kolom”

$$
\begin{gathered}
\frac{P_{r}}{\emptyset P_{c}}+\frac{8}{9}\left(\frac{M_{r x}}{M_{c x}}+\frac{M_{r y}}{M_{c y}}\right) \leq 1,0 \\
0,33+\frac{8}{9}\left(\frac{196.886,98}{533.500}+\frac{201.557,86}{533.500}\right) \leq 1,0 \\
0,993 \leq 1,0(\mathrm{OK})
\end{gathered}
$$

Kontrol Strong Column Weak Beam:

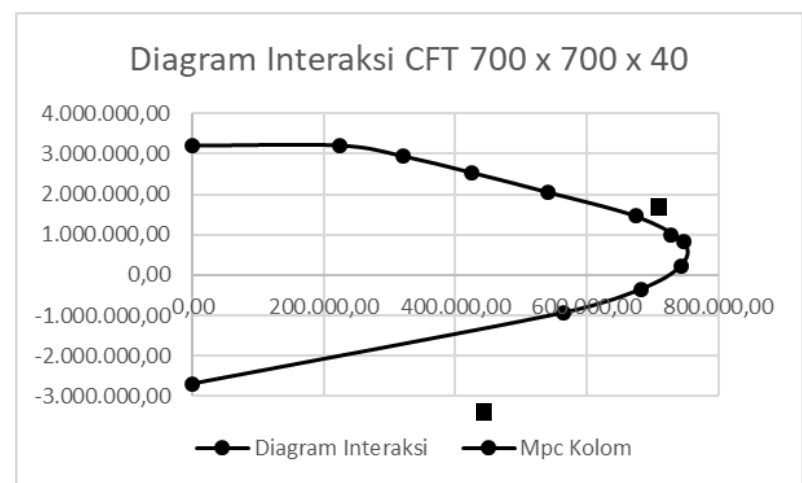

Gambar 9. Diagram Interaksi CFT

$\Sigma \mathrm{M}^{*} \mathrm{pc}=2 \times 72.840 .494 \mathrm{~kg} . \mathrm{cm}=145.680 .999 \mathrm{~kg} . \mathrm{cm}$

$\sum M *_{p b}=\sum\left(1,1 R_{y} f_{y} Z+M_{y}\right)$

$$
=2 \times(1,1 \times 1,5 \times 2.500 \times 5.017+337.395,56 \times 100)
$$

$=108.869 .362 \mathrm{~kg} . \mathrm{cm}$

$\frac{\sum M * p c}{\sum M * p b}=\frac{1.456,91}{1.088,69}=1,33(\mathrm{OK} !)$

Dikarenakan struktur sudah dikontrol secara strong column weak beam, maka bisa dipastikan bahwa balok dapat berdeformasi sementara kolom tetap kuat. Maka sistem struktur sistem ganda rangka baja dengan bresing eksentris dapat digunakan untuk permodelan ini.

\section{E. Perencanaan Sambungan}

1) Perencanaan Sambungan Sekunder

Pada perencanaan sambungan, direncanakan baut dengan mutu A325 dan pelat penyambung profil siku dengan mutu BJ41. Hasil perhitungan sambungan struktur sekunder

\begin{tabular}{|c|c|c|c|c|}
\hline \multicolumn{2}{|c|}{ Elemen } & \multirow{3}{*}{$\begin{array}{l}\text { Profil Siku } \\
\text { L19.19.1,4 }\end{array}$} & \multirow{3}{*}{$\begin{array}{r}\mathbf{D}(\mathbf{m m}) \\
12\end{array}$} & \multirow{3}{*}{$\begin{array}{r}\mathbf{n ~ ( j b )} \\
2 \\
2\end{array}$} \\
\hline Balok anak & Badan B.Anak & & & \\
\hline $\begin{array}{l}\text { lantai - balok } \\
\text { Induk }\end{array}$ & Badan B.Induk & & & \\
\hline \multirow{2}{*}{$\begin{array}{l}\text { Balok utama } \\
\text { tangga - } \\
\text { penumpu } \\
\text { tangga }\end{array}$} & $\begin{array}{l}\text { Badan B.Utama } \\
\text { Tangga }\end{array}$ & & & 2 \\
\hline & $\begin{array}{l}\text { Badan } \\
\text { B.Penumpu } \\
\text { Tangga }\end{array}$ & L60.60.6 & 12 & 2 \\
\hline \multirow{2}{*}{$\begin{array}{l}\text { Balok } \\
\text { penumpu } \\
\text { tangga - } \\
\text { kolom }\end{array}$} & $\begin{array}{l}\text { Badan } \\
\text { B.Penumpu } \\
\text { Tangga }\end{array}$ & L60.60.6 & 12 & 2 \\
\hline & Sisi kolom & Las Sudut & Las3 mm & \\
\hline
\end{tabular}
terlampir pada Tabel 8.

Tabel 8.

Sambungan Struktur Sekunder

\section{2) Sambungan Struktur Primer}

Pada perencanaan sambungan, direncanakan baut dengan mutu A325 dan A490, mutu las $\mathrm{FE}_{70 \mathrm{xx}}$, dan pelat penyambung mutu BJ-41. Hasil perhitungan sambungan struktur primer

\begin{tabular}{|c|c|c|c|c|}
\hline Elemen & $\begin{array}{c}\text { D badan } \\
(\mathrm{mm})\end{array}$ & $\begin{array}{c}\text { n badan } \\
\text { (buah) }\end{array}$ & $\begin{array}{l}\text { D sayap } \\
(\mathrm{mm})\end{array}$ & $\begin{array}{c}\text { n sayap } \\
\text { (buah) }\end{array}$ \\
\hline $\begin{array}{l}\text { Balok Induk - end plate } \\
2 \mathrm{~cm} \text { untuk sambungan } \\
\text { balok induk - link }\end{array}$ & & Las tump & $\mathrm{ll} 2 \mathrm{~cm}$ & \\
\hline $\begin{array}{l}\text { Balok link - end plate } 2 \\
\text { cm untuk sambungan } \\
\text { balok induk - link }\end{array}$ & & Las tump & $\mathrm{ll} 2 \mathrm{~cm}$ & \\
\hline $\begin{array}{l}\text { Sambungan balok induk } \\
\text { - link (pada masing } 2 \text { end } \\
\text { plate) }\end{array}$ & 27 & 10 & - & - \\
\hline Bresing - balok induk & & Las tumpı & $1,9 \mathrm{~cm}$ & \\
\hline Bresing - kolom & & Las tumpi & $1,9 \mathrm{~cm}$ & \\
\hline Bresing - buhul & & Las tump & $1,9 \mathrm{~cm}$ & \\
\hline $\begin{array}{l}\text { Buhul bresing - balok } \\
\text { induk }\end{array}$ & & Las tump & $1,9 \mathrm{~cm}$ & \\
\hline $\begin{array}{l}\text { Kolom - diafragma }(\mathrm{tp}= \\
2,3 \mathrm{~cm})\end{array}$ & & Las sudu & $2,1 \mathrm{~cm}$ & \\
\hline $\begin{array}{l}\text { Channel kolom }- \text { web } \\
\text { balok }(\mathrm{tp}=1,4 \mathrm{~cm})\end{array}$ & & Las sudu & $1,2 \mathrm{~cm}$ & \\
\hline $\begin{array}{l}\text { Diafragma kolom }- \\
\text { flange balok (tp }=2,3 \\
\mathrm{~cm})\end{array}$ & & Las sudu & $2,1 \mathrm{~cm}$ & \\
\hline $\begin{array}{l}\text { Sambungan diafragma - } \\
\text { diafragma }(\mathrm{tp}=2,3 \mathrm{~cm})\end{array}$ & & Las tump & $2,3 \mathrm{~cm}$ & \\
\hline $\begin{array}{l}\text { Sambungan diafragma - } \\
\text { flange balok }\end{array}$ & & Las tump & $2,3 \mathrm{~cm}$ & \\
\hline Antar Kolom & & Las tump & $\mathrm{ll} 4 \mathrm{~cm}$ & \\
\hline Kolom - Base Plate & T Plat $=$ & $5 \mathrm{~cm}$ & $\mathrm{~N}$ angkur & 8M25 \\
\hline
\end{tabular}
tersaji pada Tabel 9.

Tabel 9.

Sambungan Struktur Primer

\section{F. Perhitungan Struktur Bawah}

1) Dinding Basement

Dinding basement direncanakan menerima tekanan horizontal tanah, yang kemudian dimasukkan ke dalam aplikasi permodelan, kemudian di dapat momen seperti pada Gambar 10.

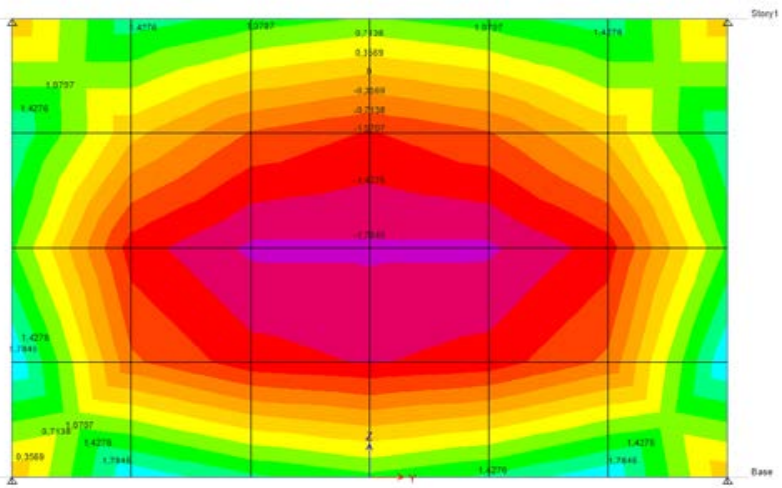

Gambar 10. Momen pada Dinding Basement

Kemudian didapat dimension dari dinding yang direncanakan sebagai berikut:

Tebal dinding $=300 \mathrm{~mm}$.

Tulangan = D16-200 mm .

Kemudian didapat gambar potongan dinding dan pelat basement seperti pada Gambar 11. 


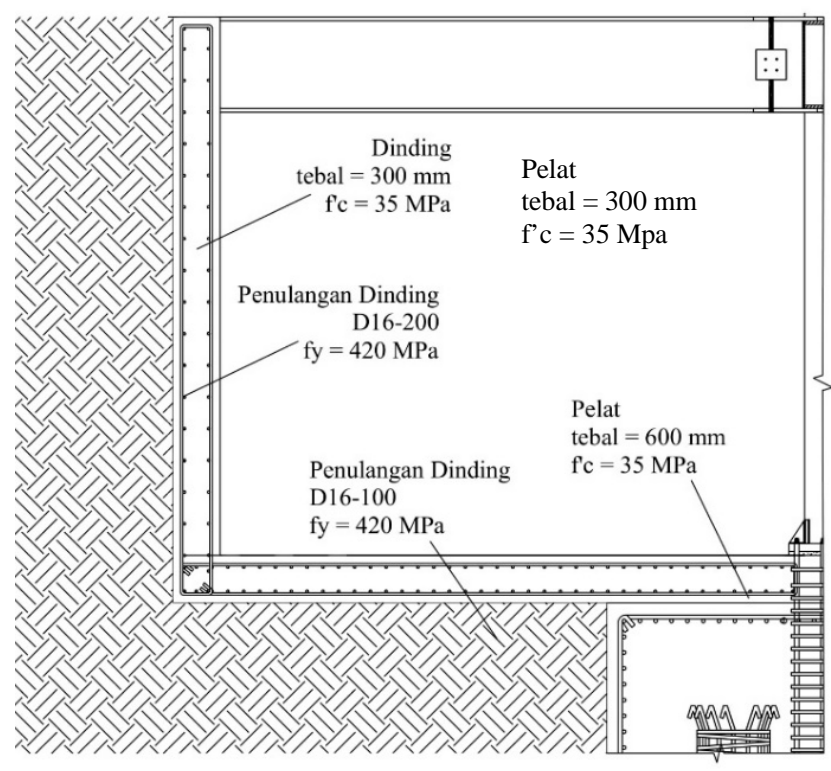

Gambar 11. Tampak Dinding dan Pelat Basement

2) Pelat Basement

Berikut merupakan rekapitulasi penulangan pada Basement.

Tebal pelat $=300 \mathrm{~mm}$.

Tabel 10.

Penulangan Pelat Basement

\begin{tabular}{cccc}
\hline \multicolumn{3}{c}{ Bentang } & \multicolumn{3}{c}{ Penulangan } \\
\hline Lx & Ly & $\mathbf{X}$ & $\mathbf{Y}$ \\
\hline 6 & 6 & D16-100 & D16-100 \\
6 & 5,5 & D16-100 & D16-100 \\
5,5 & 6 & D16-100 & D16-100 \\
5,5 & 5,5 & D16-100 & D16-100 \\
\hline \hline
\end{tabular}

3) Pondasi Tiang Pancang

Pondasi yang digunakan pada perencanaan gedung apartemen berasal dari spun pile produk dari PT. Waskita Beton Precast dengan tipe A1 diameter $800 \mathrm{~mm}$ dengan kedalaman -30 m dan panjang bersih 28,5 m. Denah Pondasi yang didapat sesuai dengan Gambar 12.

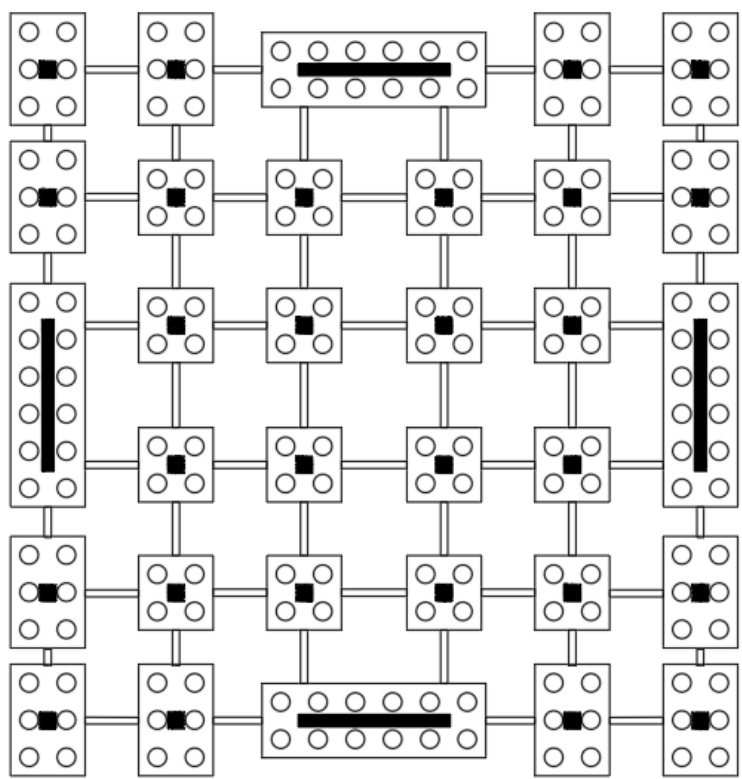

\section{4) Perencanaan Poer}

Untuk penulangan lentur, poer dianalisa sebagai balok kantilever dengan perletakan jepit pada kolom. Dan beban yang bekerja adalah beban terpusat di tiang kolom yang menyebabkan reaksi pada tanah dan berat sendiri poer. ${ }^{[10]}$. Berikut adalah hasil perhitungan untuk dimensi poer :

Tabel 11.

Jumlah Tulangan pada Pile Cap

\begin{tabular}{cccc}
\hline \hline Tipe Poer & \multirow{2}{*}{ Bagian } & \multicolumn{2}{c}{ Tulangan } \\
\cline { 1 - 1 } Dimensi & & Sumbu X & Sumbu Y \\
\hline Tipe 1 & Atas & D25-100 & D25-100 \\
3,2×4,8×1,3 & Bawah & D25-100 & D25-100 \\
Tipe 2 & Atas & D32-100 & D32-100 \\
3,2×3,2×1,3 & Bawah & D32-100 & D32-100 \\
Tipe 3 & Atas & D36-100 & D36-100 \\
$3,2 \times 9,6 \times 1,3$ & Bawah & D36-200 & D36-200 \\
Tipe 4 & Atas & D36-200 & D36-200 \\
$9,6 \times 3,2 \times 1,3$ & Bawah & D36-100 & D36-100 \\
\hline \hline
\end{tabular}

5) Sloof

Sloof direncanakan menggunakan tulangan baja, hal tersebut dilakukan karena Sloof menerima kombinasi beban aksial tekan dan lentur dimensi 300x400 mm.

$$
\begin{array}{ll}
\mathrm{qu} & =1,4 \times 0,3 \times 0,4 \times 2400=403,2 \mathrm{~kg} / \mathrm{m} \\
\mathrm{Mu} \text { tumpuan } & =5071,95 \mathrm{kgm}=50,7 \mathrm{kNm} \\
\mathrm{Pu} \text { Sloof } & 609 \mathrm{kN} \\
\text { Dipasang tulangan }= & 12 \mathrm{D} 19\left(A_{s}=3400 \mathrm{~mm}^{2}\right) \text { dan } \\
& \quad \text { sengkang } 2 \varnothing 10-150 \mathrm{~mm}
\end{array}
$$

6) Perencanaan tusuk konde tiang pancang.

Kolom di dalam tiang pancang direncanakan dengan diameter kolom sebesar $800-2 \times 120=560 \mathrm{~mm}$.

Tusuk konde direncanakan sebesar 7D22 mm, sedangkan untuk sengkang spiral didapat tulangan D19-30 mm.

\section{KESIMPULAN DAN SARAN}

A. Kesimpulan

1. Hasil perhitungan pada struktur sekunder telah memenuhi syarat terhadap kontrol kuat penampang, kontrol geser dan lendutan yang mengacu kepada SNI 1729:2015 untuk struktur baja dan SNI 2847:2013 untuk struktur beton.

2. Dari kontrol yang dilakukan, kontrol yang direncanakan berada di kota Jogjakarta telah memenuhi syarat yang terdapat pada SNI 1729:2015 (analisis struktur dapat digunakan).

3. Hasil analisa struktur primer yang dilakukan telah memenuhi syarat terhadap kontrol kuat penampang, kontrol geser, kontrol sudut rotasi link, kontrol interaksi geser lentur dan lendutan yang mengacu kepada SNI 1729:2015 dan SNI 1729:2002 untuk struktur baja dan SNI 2847:2013 untuk struktur beton.

4. Perhitungan pada struktur bawah telah memenuhi persyaratan dimensi dan kontrol akibat beban dari luar.

\section{B. Saran}

Saran untuk perencanaan ini adalah diperlukan pengawasan yang baik dan benar dalam pelaksanaan di lapangan sehingga struktur dapat benar-benar bekerja sebagai struktur rangka baja dan beton komposit dengan bresing eksentris. 


\section{DAFTAR PUSTAKA}

[1] A. F. Muharam, "Modifikasi Perencanaan Struktur Apartemen One East Residence Surabaya dengan Struktur Komposit Baja Beton dan Base Isolator: High Damping Rubber Bearing,” Institut Teknologi Sepuluh Nopember, 2017.

[2] C. W. Roeder, D. E. Lehman, and E. Bishop, "Strength and stiffness of circular concrete-filled tubes,” J. Struct. Eng., vol. 136, no. 12, pp. 1545-1553, Dec. 2010.
[3] S. P. Schneider, D. R. Kramer, and D. L. Sarkkinen, "The design and construction of concrete-filled steel tube column frames," in 13th World Conference on Earthquake Engineering, 2004.

[4] S. K. Azad and C. Topkaya, "A review of research on steel eccentrically braced frames,” J. Constr. Steel Res., vol. 128, pp. 53-73, Jan. 2017.

[5] American Institute of Steel Construction, "Seismic Provision for Structural Steel Buildings,” 2010. 